\title{
Los nuevos delitos contra la seguridad vial: una muestra de la Administración del Derecho Penal
}

\author{
Raquel Montaner Fernández \\ Profesora Derecho Penal. Universidad Pompeu Fabra
}

\begin{abstract}
Resumen
Tradicionalmente, los delitos contra la seguridad vial vienen considerándose como delitos de peligro. Sin embargo, con la última reforma penal en esta materia el legislador se aleja de la técnica de los delitos de peligro introduciendo tipos penales más formales. De este modo, el Derecho Penal cada vez se aproxima más a la lógica del Derecho administrativo sancionador, aparcando la relevancia de principios que tradicionalmente han inspirado el lus puniendi como es el principio de lesividad. El delito de conducción a una velocidad excesiva (art. 379.1) y el delito de conducción sin permiso o licencia (art. 384) son dos de las manifestaciones de esta nueva orientación del Derecho penal.
\end{abstract}

Palabras clave

Peligrosidad, seguridad, principio de lesividad, delito formal.

\section{The news crimes againts the road safety: a sample of the administration of the criminal law}

\begin{abstract}
Traditionally, the road traffic offences are considered as dangerousness offences. Nevertheless, with the last criminal law reform in this area the legislator mover away from the dangerousness offences to get closer to more formal offences. In this way, the Criminal Law is coming closer so the sanctioning Administrative Law system, forgetting the relevance of some traditional principles in lus puniendi like the harm principle. The offence of driving at an excessive speed (art. $379.1 \mathrm{CP}$ ) and the offence of driving without driving license (art. $384(P)$ are two examples of this new Criminal Law orientation.
\end{abstract}

Key words

Dangerousness, security, harm principle, formal offence. 


\section{INTRODUCCIÓN}

Los delitos contra la seguridad vial están regulados en los arts. 379 a 385 del CP, imbricados, a su vez, en el Título XVII “De los delitos contra la seguridad colectiva”. La última gran reforma de estos tipos penales tiene lugar con la LO 15/2007, de 30 de noviembre, por la que se modifica el Código en materia de Seguridad Vial'. Además del cambio de denominación -pues anteriormente el CP hacía referencia a los "delitos contra la seguridad del tráfico"-, esta ley supone, por un lado, la modificación de algunos de los términos de las figuras delictivas previstas hasta el momento y, por otro lado, la introducción de nuevos tipos penales. Así por ejemplo, con esta reforma, por cierto no exenta de críticas², junto al ya regulado delito de conducción bajo la influencia de bebidas alcohólicas u otras sustancias, se introduce un nuevo tipo penal que castiga la conducción con altas tasas de alcohol (art. 379.2 in fine) y otro que tipifica la conducción a una velocidad excesiva (art. 379.1). Otra de las novedades es que con la LO 15/2007 el legislador vuelve a castigar penalmente conductas que desde el año 1983 se hallaban despenalizadas, como es el caso de la conducción sin permiso3, ahora regulada en el art. 384 CP. En cualquier caso, todos estos cambios legislativos responden al objetivo primordial de la reforma operada por la LO 15/2007 que, según se señala en su Exposición de Motivos, no es otro que el de "incrementar el control sobre el riesgo tolerable" penalmente. En esta medida, es una muestra más del denominado por Silva Sánchez fenómeno de la "expansión del Derecho penal”“ y, de ahí, de la "ampliación constante de la intervención penal" través de la intervención del Derecho penal no solamente se reducen los espacios de riesgo tolerables sino que, además, se aseguran de forma efectiva espacios de seguridad $^{6}$. Ahora bien, lo problemático es que esta ampliación de los ámbitos de intervención del Derecho penal no siempre se realiza de una forma pacíficamente compatible con los principios y garantías que tradicionalmente han inspirado al Derecho penal como lus puniendi, esto es, como derecho del Estado a castigar. Así por ejemmplo, a medida que la aplicación del Derecho penal se plantea en ámbitos muy distintos del conocido "Derecho penal nuclear", parece necesario recurrir a otras técnicas o criterios de intervención que, entre otros aspectos, pueden poner en tela de juicio principios básicos como es el de ultima ratio o el principio de lesividad. Así, en deter-

1 La Ley Orgánica 5/2010, de 22 de junio, por la que se modifica la Ley Orgánica 10/1995, de 23 de noviembre, del Código Penal, también introduce algunos cambios en la regulación de los delitos contra la seguridad vial.

2 Al respecto, Queralt i Jiménez, en Seguridad Vial y Derecho penal, pp. 63-71.

3 Anteriormente, la Ley $3 / 1967$, de 8 de abril, sobre modificación de determinados artículos del Código Penal y de Ley de Enjuiciamiento Criminal introdujo el delito de conducción ilegal en el art. 340 bis c) del Texto Refundido de 1973, cuyo tenor literal era el siguiente: "Será castigado con pena de multa de cinco mil a veinte mil pesetas el que condujere por vía pública un vehículo de motor sin haber obtenido el correspondiente permiso".

4 Vid. Silva Sánchez, La Expansión del Derecho penal, $2^{\text {a }}$ ed.

5 Así, Mir Puig, en Seguridad Vial y Derecho penal, pp. 14-18; en el mismo sentido, Feijóo Sánchez, Derecho y justicia penal en el s. XXI, p. 138.

6 Recientemente, destacando la "preocupación especial por la seguridad" característica de nuestra sociedad, Gutiérrez Rodríguez (et. al.), Protección penal de la seguridad vial, p. 25. 
minados contextos, la técnica de los delitos de lesión se presenta como insuficiente o, por lo menos, no como la más efectiva para afrontar los nuevos ámbitos de criminalidad. Como consecuencia, proliferan los tipos penales configurados como delitos de peligro, ya sea de peligro concreto o de peligro abstracto.

Desde la doctrina se alude a la existencia de una estrecha vinculación entre la técnica legislativa de tutela (delitos de lesión o de peligro) y el objeto tutelado a través de la norma penal7. Así, la tutela a través de los delitos de lesión normalmente operaría para la protección de bienes jurídicos individuales, mientras que la técnica de los delitos de peligro se relacionaría con la protección de bienes jurídicos supraindividuales o colectivos ${ }^{8}$. Ahora bien, los delitos de peligro también son una herramienta idónea para la protección de bienes jurídicos individuales, pues en tanto que permiten un adelantamiento de las barreras de intervención del Derecho penal, su protección ya es posible en el momento en que se realiza una conducta para ellos peligrosa, sin necesidad de esperar a que se produzca la lesión. En esta medida, para una parte de la doctrina, el delito de peligro solamente tiene sentido en la tutela de los bienes jurídico-penales individuales que, en ese caso, se ponen en peligro pero no se lesionan?. Tradicionalmente, los delitos contra la seguridad vial han sido considerados delitos de peligro, algunos de peligro concreto - como el de conducción temeraria del art. 380-y otros de peligro abstracto -como es el caso del delito de conducción bajo la influencia de bebidas alcohólicas del art. 379.2-. Lo que no resulta tan sencillo es determinar cuál es el bien jurídico protegido a través de estas figuras delictivas ${ }^{10}$. Al respecto, algunos entienden que lo protegido es la seguridad vial, como bien jurídico colectivo autónomo, para otros, lo realmente protegido son los bienes jurídicos individuales (vida y salud de las personas) que pueden resultar afectados como consecuencia de ciertos modos de conducción ${ }^{11}$. Por último, una postura intermedia entiende que se protegen simultáneamente "bienes jurídicos singulares y generales"12, esto es, bienes jurídicos personales y suprapersonales como la seguridad del tráfico. A mi juicio, los delitos contra la seguridad vial no pueden desvincularse de la protección de bienes jurídicos individuales. Si bien cabe aceptar su reconocimiento como circunstancia o realidad relevante para el desarrollo de intereses individuales, la seguridad vial no posee sustantividad propia y autónoma como para configurarse como bien jurídico-penal. Aho-

7 Vid. Mata Martín, Bienes jurídicos intermedios, pp. 47-48; en el mismo sentido, Hefendehl, en Estudios penales en homenaje a Enrique Gimbernat, t. I, p. 390.

8 Vid. Corcoy Bidasolo, en CGPJ: Derecho penal del s. XXI, p. 368.

9 Vid. Corcoy Bidasolo, en CGPJ: Derecho penal del s. XXI, p. 368, p. 376, señalando además que "si lo que se protege es el bien jurídico-penal supraindividual, éste resulta efectivamente lesionado -afectado- con la realización de la conducta típica, por lo que carece de sentido su denominación de "delitos de peligro"”, pp. 368-369. A propósito del medio ambiente, Alcácer Guirao, RECPC 2002, Ilega a la misma conclusión en caso de que aquél bien jurídico sea entendido como objeto autónomo de tutela, $v$. p. 5.

10 Sobre las distintas posturas doctrinales mantenidas al respecto, vid. Gutiérrez Rodríguez (et. al.), Protección penal de la seguridad vial, pp. 27-36.

11 A favor de esta segunda interpretación, entre otros, Hefendehl, RECPC 04-14 (2002); el mismo, en La teoría del bien jurídico, p. 191; Moreno Alcázar, Los delitos de conducción temeraria, para quien lo directa e inmediatamente protegido son los bienes jurídicos individuales, en concreto la vida e integridad física, siendo la seguridad del tráfico un bien sin autonomía propia, p. 51 y ss.

12 Vid. Mata Martín, Bienes jurídicos intermedios, p. 26. 
ra bien, tampoco es acertado sostener que lo directamente protegido son bienes individuales, pues el Derecho penal regula los delitos contra la seguridad vial sobre la base de la preexistencia de un "bien jurídico-seguridad vial" reconocido en otro sector del ordenamiento. Sin embargo, la "importancia fundamental" que caracteriza a los bienes jurídicos penales se sustenta en este caso en su vinculación a intereses personales fundamentales. Así pues, no es concebible la seguridad vial sin su vinculación a bienes jurídicos individuales como la vida o salud de las personas. Lo que el Derecho penal quiere evitar es que en este determinado contexto de actividad se lleven a cabo conductas con potencialidad lesiva para esos intereses personales fundamentales. Por tanto, cuando se califica a los delitos contra la seguridad vial como delitos de peligro, resulta inevitable valorar este peligro desde la perspectiva de su capacidad de afectación a bienes jurídicos individuales ${ }^{13}$. Sólo así tiene sentido referirse al adelantamiento de protección como efecto de los delitos de peligro ${ }^{14}$. Pero no se trata de la protección directa de bienes individuales. Para ello ya disponemos de otros preceptos. Lo que se protege aquí es la seguridad vial, como interés general en que se desarrolle adecuadamente una actividad potencialmente lesiva para los participantes en el tráfico. En otras palabras, lo que pretenden estos preceptos es mantener la circulación vial libre y exenta de todo peligro, daño o riesgo para las personas. En definitiva, estamos ante un bien jurídico mixto, pues a diferencia de los bienes supraindividuales, la seguridad vial no posee un sustento constitucional que legitime su autonomía como interés socialmente reconocido. Con ello, es inevitable su vinculación a derechos individuales que sí disfrutan de reconocimiento constitucional.

Resuelta la cuestión de cuál es el bien jurídico protegido mediante estos delitos, es preciso retomar el análisis respecto a la técnica de tutela utilizada, esto es, los delitos de peligro. Pues bien, más allá de la problemática general respecto a la utilización de los delitos de peligro, lo que se plantea a propósito de la nueva regulación penal de la seguridad vial, y especialmente respecto a alguna de las figuras delictivas, es si continúa siendo posible afirmar que se trata de delitos de peligro respetuosos con el principio de lesividad o si, por el contrario, estamos ante conductas típicas meramente formales y desvinculadas de cualquier lesividad al bien jurídico protegido ${ }^{15}$. En mi opinión, esto puede plantearse, por ejemplo, en relación con el nuevo delito de conducción a una velocidad excesiva del art. $379.1^{16}$ y con respecto al también nuevo delito de conducción sin permiso del art. $384 \mathrm{CP}$, pues se trata de tipos penales de los que, como mucho, cabría afirmar que responden a la lógica de los delitos de peligro abstracto ${ }^{17}$.

13 En este sentido, Orts Berenguer, en Derecho penal. PE, 2. ${ }^{a}$ ed., p. 590.

14 En este sentido, Sola Reche, RGDP10 (2008), pp. 10-11.

15 Al respecto, Gutiérrez Rodríguez (et. al.), Protección penal de la seguridad vial, señalan que "la nueva regulación acentúa el carácter colectivo del objeto de tutela penal (...), otorgando al Derecho penal una función en cierta medida accesoria respecto al Derecho administrativo sancionador, al atribuirle la función de reforzar, a través de la pena, la normativa administrativa orientada a gestionar el riesgo derivado del tráfico viario, de forma que éste se desarrolle en condiciones de seguridad", p. 31.

16 En este sentido, Requejo Conde, Tráfico y Seguridad Vial (La Ley) 2009, p. 8, señalando que se trata de conductas más próximas a las infracciones administrativas.

17 En esta misma línea, Gutiérrez Rodriguez (et. al.), Protección penal de la seguridad vial, p. 36. 
Así pues, tomando como referencia estas dos modalidades delictivas, lo que se pretende analizar en este trabajo es si con la tipificación de estas nuevas conductas el Derecho penal sigue manteniéndose en los límites que tradicionalmente lo han inspirado -entre ellos, el principio de lesividad u ofensividad-o si, por el contrario, adopta una nueva lógica de tipificación mucha más próxima al Derecho administrativo sancionador. En definitiva, se trata de determinar qué es lo que le preocupa al Derecho penal en el ámbito de la seguridad vial, qué es lo que pretende. De ahí que quepa diferenciar dos posibles interrogantes: a) ¿Lo que preocupa es que, realizando estas conductas, se lesione o se ponga en peligro el bien jurídico-penal protegido?; b) o bien se trata de plantearse ¿qué pasaría si todos los participantes en el tráfico vial realizaran esas conductas?

A los efectos de ofrecer una respuesta a esta cuestión, es necesario atender de manera previa no sólo a los rasgos definitorios de las dos figuras delictivas a las que se prestará atención, sino también a los elementos que configuran el Derecho penal moderno. De este modo, se atenderá a las distintas modalidades de los delitos de peligro, a su relación con el denominado fenómeno de la administrativización del Derecho penal y, de ahí, a las consecuencias que ello implica.

\section{EL DELITO DE CONDUCCIÓN A VELOCIDAD EXCESIVA (ART. 379.1 CP)}

Conforme a las estadísticas que anualmente publica la Dirección General de Tráfico, la conducción a una velocidad inadecuada es un de los factores más significativos de los accidentes con víctimas. Así por ejemplo, en el año 2008 , en un $28 \%$ de los accidentes mortales producidos se apreció que la velocidad era un factor concurrente del accidente (www.dgt.es). Precisamente, en el art. 379.1 CP se tipifica una modalidad de conducción de vehículos a motor o ciclomotores relacionada con la velocidad. Tras la LO 5/2010, de 22 de junio, el tenor literal de este precepto es el siguiente:

\footnotetext{
"El que condujere un vehículo de motor o un ciclomotor a velocidad superior en sesenta kilómetros por hora en vía urbana o en ochenta kilómetros por hora en vía interurbana a la permitida reglamentariamente, será castigado con la pena de prisión de tres a seis meses o a la de multa de seis a doce meses o con la de trabajos en beneficio de la comunidad de treinta y uno a noventa días, y, en cualquier caso, a la de privación del derecho a conducir vehículos a motor y ciclomotores por tiempo superior a uno y hasta cuatro años".
}

Con base en la configuración de la conducta típica del art. 379.1 CP, a saber, conducir un vehículo a motor o ciclomotor por vías públicas superando la velocidad permitida en $60 \mathrm{kms} / \mathrm{h}$. en vía urbana o en $80 \mathrm{kms} / \mathrm{h}$. en vía unterurbana, la determinación de la tipicidad penal requiere recurrir a los límites de velocidad previstos en la regulación administrativa. De este modo, este tipo penal se configura como una ley penal en blanco que necesita ser completada ${ }^{18}$. En este sentido, la norma que servirá

18 Vid. Gutiérrez Rodríguez, en Gutiérrez Rodríguez (et. al.), Protección penal de la seguridad vial, p. 50, pp. 51-52. 
de complemento es el RD 1428/2003, de 21 de noviembre, que aprueba el Reglamento General de Circulación, y que establece en el art. 47 y ss. las velocidades máximas y mínimas permitidas. El art. 48, por su parte, especifica las velocidades máximas permitidas en vías interurbanas. Así por ejemplo, según el art. 48.1.a), en autopistas y autovías, la velocidad máxima a la que pueden circular los turismos y motocicletas es de $120 \mathrm{kms} / \mathrm{h}$.; la de los autobuses, vehículos derivados de turismo y vehículos mixtos adaptables es de 100 kms/h.; la de los camiones, vehículos articulados, tractocamiones, furgones y automóviles con remolque de hasta $750 \mathrm{kgs.,}$ de $90 \mathrm{kms} / \mathrm{h}$.; y la de los restantes automóviles con remolque, de $80 \mathrm{kms} / \mathrm{h}$. En las carreteras convencionales y en el resto de vías fuera de poblado los límites de velocidad asignados a cada tipo de automóvil son más bajos (art. 48.1.a), $2 .^{\circ}, 3 . .^{\circ}$ y $4 .^{\circ}$ ). Por otra parte, el art. 50 del mismo Reglamento establece que, con carácter general, el límite máximo de velocidad en vía urbana es de $50 \mathrm{kms} / \mathrm{h}$. y de $40 \mathrm{kms} / \mathrm{h}$. para los vehículos que transportan mercancías peligrosas. Así pues, sobre la base de los límites previstos en la normativa administrativista y de los excesos a los que se refiere el Código penal, será delito conducir, por ejemplo, a $110 \mathrm{kms} / \mathrm{h}$. en vía urbana o a $200 \mathrm{kms} / \mathrm{h}$. en vía interurbana. Por tanto, los excesos de velocidad que queden por debajo de los $60 \mathrm{kms} / \mathrm{h}$. u $80 \mathrm{kms} / \mathrm{h}$. (en función del tipo de vía) constituirán, en principio, infracción administrativa y no penal.

Ahora bien, una vez diferenciados los supuestos de conducción excesiva que constituyen delito de aquellos que simplemente constituyen infracción administrativa, la existencia de delito dependerá solamente de la constatación de que se hayan superado los parámetros de velocidad previstos en el tipo y que se tengan por peligrosos ${ }^{19}$. De este modo, la distinción entre ilícito administrativo e ilícito penal es de naturaleza exclusivamente cuantitativa ${ }^{20}$. De ahí se deriva una de las mayores críticas que se formulan a esta nueva figura delictiva, a saber, que se trata de un delito de peligro presunto (o abstracto puro) y que, con ello, se produce un "desgaste" de principios como el de ofensividad y el de intervención mínima del Derecho penal ${ }^{21}$. Esto es, mediante esta regulación el legislador está reconociendo que esta conducción a una velocidad excesiva es per se peligrosa, sin necesidad de constatar que con ella se crea un peligro para las personas que intervienen en el tráfico rodado.

19 En este sentido, en el Preámbulo la LO 15/2007, de 30 de noviembre, se manifiesta que uno de los objetivos que se persiguen es "incrementar el control sobre el riesgo tolerable por la vía de la expresa previsión de excesos de velocidad que se han de tener por peligrosos”(la cursiva es mía).

20 En el mismo sentido, Sola Reche, $R G D P 10$ (2008), p. 16; Gutiérrez Rodríguez, en Protección penal de la seguridad vial, p. 51.

21 Vid. De Vicente Martínez, Derecho penal de la circulación, 2 ed., p. 499; García Albero, RECPC 0911 (2007), p. 10, señalando que aquí el legislador penal se ha guiado por criterios estrictamente simbólicos, de manera que "la lesividad concreta del comportamiento pierde importancia: el exceso de velocidad es la causa de muchos accidentes y es preciso configurar una infracción que "comunique" socialmente”, p. 11; también, Gutiérrez Rodríguez, en Protección penal de la seguridad vial, pp. 67-70, entendiendo que, en vía interpretativa, "los supuestos en los que la conducta no revele ningún tipo de peligrosidad para la circula310 ción (...) deberían quedar excluidos del tipo penal, en atención a los principios de lesividad y fragmentarie- 


\title{
III. EL DELITO DE CONDUCCIÓN SIN PERMISO (ART. 384)
}

Como se señala en el Preámbulo de la LO 15/2007, dando respuesta a una criticada ausencia, el legislador tipifica una serie de conductas en el art. 384 CP, cuyo tenor literal es el siguiente:

\begin{abstract}
"El que condujere un vehículo de motor o ciclomotor en los casos de pérdida de vigencia del permiso o licencia por pérdida total de los puntos asignados legalmente, será castigado con la pena de prisión de tres a seis meses o con la de multa de doce a veinticuatro meses o con la de trabajos en beneficio de la comunidad de treinta y uno a noventa días.

La misma pena se impondrán al que realizare la conducción tras haber sido privado cautelar o definitivamente del permiso o licencia por decisión judicial y al que condujere un vehículo de motor o ciclomotor sin haber obtenido nunca permiso o licencia de conducción".
\end{abstract}

Sin perjuicio de que seguidamente se analizarán las distintas modalidades de conducta típica previstas en este precepto, cabe afirmar que, de forma general, el art. 384 CP castiga la conducción de un vehículo a motor o ciclomotor sin estar autorizado, esto es, de forma ilegal. A partir de aquí, se distinguen tres clases de conducta: la conducción pese a no tener vigente el permiso o licencia por pérdida de los puntos; la conducción aun habiendo perdido cautelar o definitivamente el permiso o licencia por decisión judicial; y, por último, la conducción sin haber obtenido nunca el permiso o licencia. Veamos, muy brevemente, las características básicas de cada una de estas figuras delictivas ${ }^{22}$.

En primer lugar, para fundamentar la tipicidad penal en casos de conducción pese a no estar vigente el permiso o licencia de conducción por pérdida de los puntos administrativamente asignados es necesario recurrir a lo dispuesto en la Ley 17/2005, de 19 de julio, reguladora del denominado permiso y licencia de conducción por puntos y que modifica el Texto articulado de la Ley sobre Tráfico ${ }^{23}$. De este modo, volvemos a estar ante un tipo penal configurado como ley penal en blanco ${ }^{24}$. Pues bien, la más arriba mencionada norma administrativa prevé un sistema de crédito en puntos -inicialmente, 12 puntos- con el que cuenta cada conductor titular del permiso o licencia de conducción y de cuyo mantenimiento también depende la vigencia del permiso o licencia. La pérdida de todos los puntos implica que el titular del permiso ha cometido diversas infracciones administrativas y, a partir de aquí, el Derecho penal interviene cuando el conductor infractor, aun haber agotado su crédito de puntos, conduce un vehículo a motor o ciclomotor.

22 Sobre un análisis más detenido de esta figura delictiva, vid. García del Blanco, en Protección penal de la seguridad vial, p. 399 y ss.; también, Montaner Fernández, Diario La Ley 7170 (2009).

23 BOE núm. 172, de 20 de julio de 2005.

24 Vid. García del Blanco, en Protección penal de la seguridad vial, p. 403. 
En segundo lugar, en el art. 384 CP también se castiga la conducción habiendo perdido cautelar o definitivamente el permiso o licencia por decisión judicial. Con ello, por un lado, se castiga la conducción infringiendo una medida cautelar de privación del permiso o licencia de conducir impuesta judicialmente. Según la LECrim, en el marco de los procedimientos abreviados, cabe acordar "la intervención inmediata del vehículo y la retención del permiso de circulación del mismo, por el tiempo indispensable, cuando fuere necesario practicar alguna investigación en aquel o para asegurar las responsabilidades pecuniarias, en tanto no conste acreditada la solvencia del imputado o del tercero responsable civil". Además, en este contexto la LECrim permite "la intervención del permiso de conducción requiriendo al imputado para que se abstenga de conducir vehículos de motor, en tanto subsista la medida, con la prevención de lo dispuesto en el artículo 556 del Código Penal” (art. 764.4). Por lo tanto, la finalidad que se persigue con la privación cautelar del permiso o licencia de conducción es la de asegurar la práctica de alguna investigación en el propio vehículo o las responsabilidades pecuniarias. Por ello, no parece que el objetivo de esta medida esté directamente relacionado con la seguridad vial. Por otro lado, también es típica la conducción tras la privación definitiva del permiso o licencia impuesta judicialmente, esto es, casos de pérdida de vigencia por decisión judicial.

Por último, la tercera modalidad de conducta típica prevista en el art. 384 CP es la conducción sin haber obtenido nunca el permiso o licencia de conducción. Una de las cuestiones que se plantean a propósito de esta nueva modalidad delictiva es que no siempre que se conduce sin tener el permiso o licencia se está realizando una conducta peligrosa para terceros ${ }^{25}$. Esto es, puede haber conductores con permiso más peligrosos -por ejemplo, conductores noveles- que los que no tienen permiso pero sí una gran experiencia. ¿Debe afirmarse, en cualquier caso, que concurre este tipo penal? Una solución al respecto va a depender de cuál se entienda que es el fundamento de esta regulación. Sobre ello se incidirá más adelante. En lo que sí se está de acuerdo es que no entran en este tipo ni los casos de conducción con el permiso caducado ni los de conducción con un tipo de permiso inadecuado, supuestos ambos que solamente dan lugar a una infracción administrativa (art. 65.4 m), n) y art. 65.5 j) de la Ley sobre Tráfico). Ahora bien, no está tan claro cómo solucionar aquellos casos en los que, por ejemplo, un sujeto que dispone de autorización administrativa para conducir un ciclomotor conduce un camión. Para algunos, es necesario distinguir entre los vehículos cuya conducción exige disponer de permiso de aquellos en los que para dicha actividad es necesario disponer de licencia. El permiso es la autorización administrativa que habilita para la conducción de vehículos de motor, mientras que la licencia es propia de los ciclomotores ${ }^{26}$. De este modo, entienden que casos como la conducción de un camión no disponiendo del permiso correspondiente para su manejo, aunque se disponga de una licencia para un vehículo distinto, se incluirían en el tipo del art. $384 \mathrm{CP}^{27}$.

25 En este sentido, Orts Berenguer, en Derecho penal. PE, 2. ${ }^{\text {a }}$ ed., p. 621.

26 Vid. Prieto González, en Seguridad Vial y Derecho penal, p. 276. Ahora bien, del articulado de la Ley sobre el Tráfico no se desprende esta distinción, pues en los arts. 59 y siguientes de esta norma los términos de "permiso" y "licencia" parecen equipararse.

27 Así, Prieto González, en Seguridad Vial y Derecho penal, p. 276. 
Como se apuntaba en el párrafo anterior, una cuestión fundamental para determinar en qué casos estaremos ante la existencia de este tipo penal es determinar cuál es su naturaleza, esto es, si se trata de un delito de peligro o, más bien, es un tipo formal. De entrada, cabe señalar que, al igual que en el art. 379.1 CP, en la redacción del art. 384 CP no se hace alusión alguna a la capacidad de dichas conductas de poner en peligro la seguridad vial. Así pues, quien pretenda sostener que estamos ante un tipo de peligro solamente puede hacerlo desde la perspectiva de los delitos de peligro abstracto (puro) y entendiendo que el legislador parte de una presunción de la peligrosidad de estas conductas. El problema es que no siempre es posible hablar de una peligrosidad real. En efecto, no todo el que conduzca sin permiso supone un peligro para la seguridad vial ${ }^{28}$. En esta medida, parece que el legislador ha configurado un tipo penal meramente formal. Ahora bien, según la doctrina, para evitar el automatismo en la aplicación de este tipo formal es necesario recurrir a la vía interpretativa y restringir su aplicación ${ }^{29}$.

\section{LOS DELITOS DE PELIGRO Y LA ADMINISTRATIVIZACIÓN DEL DERECHO PENAL DE LA SEGURIDAD VIAL}

\section{Planteamiento general}

Hasta la reforma que protagoniza la LO 15/2007 en materia de seguridad vial, cabía afirmar sin problemas que las figuras delictivas reguladas en este ámbito estaban configuradas como delitos de peligro. Sin embargo, actualmente, teniendo en cuenta el tenor literal de algunos de los nuevos tipos penales es mucho más discutible afirmar que una de las características de los delitos contra la seguridad vial sea su caracterización como delitos de peligro ${ }^{30}$. En este trabajo, ello se pretende poner de manifiesto a propósito de las nuevas figuras delictivas del art. 379.1 y, especialmente, del art. 384 CP. Ahora bien, a los efectos de abordar esta cuestión se hace necesario una breve aproximación a las características principales de los delitos de peligro.

Principalmente, los delitos de peligro se clasifican en delitos de peligro concreto y de peligro abstracto ${ }^{31}$. Por un lado, los delitos de peligro concreto se caracterizan por la "concreta puesta en peligro del bien jurídico" implicado, mientras que,

28 En el mismo sentido, García del Blanco, en Protección penal de la seguridad vial, p. 414.

29 Vid. García del Blanco, en Protección penal de la seguridad vial, pp. 415-416, señalando que “debe exigirse necesariamente que sean los jueces y tribunales los que determinen si dicha conducta concreta realizada sin la habilitación administrativa necesaria resultó efectivamente peligrosa en el caso concreto", p. 416.

30 En este sentido, Queralt i Jiménez, en Seguridad Vial y Derecho penal, p. 66; también, Gutiérrez Rodríguez (et. al.), Protección penal de la seguridad vial, pp. 30-32.

31 Según Corcoy Bidasolo, Delitos de peligro, p. 226 y ss., esta distinción se basa en si existe o no un resultado de peligro, mientras que para otros autores como Mir Puig, Derecho penal. PG, $8^{\mathrm{a}}$ ed., 9/60, o Peris Riera, en Estudios penales en homenaje al prof. Cobo del Rosal, p. 691, es más correcto atender a la proximidad de una concreta lesión o grado de afectación. 
por otro lado, los delitos de peligro abstracto atienden a la realización de una conducta general o estadísticamente peligrosa, sin necesidad de constatar una proximidad en la afectación al bien jurídico ${ }^{32}$. Es más, mientras que en los delitos de peligro abstracto la peligrosidad ya está determinada por el propio legislador, en los delitos de peligro concreto, en cambio, es el juez quien en el caso concreto decidirá si existe o no esa peligrosidad fundamentadora de la responsabilidad penal33. Actualmente, la mayoría de los problemas jurídicos en relación con los delitos de peligro se suscitan, precisamente, a propósito de los de peligro abstracto, tanto por su legitimidad como por su propia denominación. A raíz de ello, la doctrina penalista viene proponiendo una tercera categoría de delitos de peligro, a saber, los delitos de peligro abstracto-concreto o delitos de peligro idóneo ${ }^{34}$. Éstos, a caballo entre los delitos de peligro concreto y los de peligro abstracto, no requieren para su aplicación que el juez constate "ex post una situación de peligro concreto como resultado de peligro sino sólo que la conducta tipificada encierre una idoneidad o aptitud para lesionar o producir un daño o que se constate que supera ciertos niveles de permisión de riesgos" 35 . Aquí ya no se alude a una conducta estadísticamente peligrosa, una peligrosidad implícita a la descripción típica, sino a una conducta idónea o apta para producir determinados resultados ${ }^{36}$. Según nuestro Tribunal Supremo, si bien a propósito del delito ecológico, define el delito de peligro abstracto-concreto, también denominado delito de peligro potencial o hipotético, como un "un híbrido a medio camino entre el peligro concreto y abstracto, en el que no basta la contravención de la normativa administrativa para poder aplicarlo, sino también algo más: que la conducta sea potencialmente peligrosa (...). Lo que debe hacerse es un juicio hipotético sobre la potencialidad lesiva de la conducta, debe identificarse el riesgo creado o que la conducta es capaz de crear (...) es preciso acreditar que la conducta de que se trate, en las condiciones en que se ejecuta, además de vulnerar las normas protectoras del medio ambiente, es idónea para originar un riesgo grave para el bien jurídico protegido" ${ }^{37}$. En definitiva, mediante esta tercera categoría de delitos de peligro se pretenden salvar las críticas formuladas a los delitos de peligro abstracto en sentido estricto, en tanto que con éstos, partiendo de la lógica de la peligrosidad estadística, en realidad no se estaría castigando con base en la constatación de una peligrosidad real para el bien jurídico protegido, sino más bien atendiendo a consideraciones de peligrosidad general o presunta. Admitir que el Derecho penal puede operar bajo estos parámetros supondría reconocer que su uso no solamente está legitimado cuando, además de la infracción de ciertas normas, se cometen conductas que lesionan o ponen en peligro bienes jurídicos concretos ${ }^{38}$, sino también cuando se cometen conductas sólo peligrosas desde un punto de vista estadístico que,

32 Vid. Schröder, ZStW81 (1969), p. 7, p. 12, p. 17; Rodríguez Montañés, Delitos de peligro, pp. 14-15.

33 Vid. Schröder, ZStW 81 (1969), p. 18.

34 Vid. Schröder, ZStW 81 (1969), p. 18 y ss.

35 Feijóo Sánchez, en Homenaje al Prof. Rodríguez Mourullo, pp. 312-314 y notas 14-21.

36 Vid. Schröder, ZStW81 (1969), p. 21; Rodríguez Montañés, Delitos de peligro, p. 20.

37 Vid. STS, Sala de lo Penal, de 13 de febrero de 2008 (ponente Berdugo Gómez de la Torre).

314 mera infracción de normas, se exponen bienes jurídicos, parece justificarse una solución jurídico-penal y de 
no obstante, revelan la necesidad de gestionar ciertos riesgos sociales en beneficio de la colectividad.

Precisamente, desde esta última perspectiva se alude a la transformación del Derecho penal de herramienta al servicio de la protección de bienes jurídicos a instrumento de gestión de riesgos. Y aquí es donde la doctrina penalista viene aludiendo al fenómeno de la administrativización del Derecho penal, refiriéndose a esa tendencia del Derecho penal moderno a operar principalmente como gestor de riesgos generales ${ }^{39}$. Esto es, como herramienta jurídica para solventar riesgos colectivos. Según la doctrina, la administrativización del Derecho penal responde a dos hechos fundamentales. En primer lugar, a que una gran parte de las normas del Derecho penal postindustrial se configuran como complemento de normas y actos administrativos del Estado, esto es, son normas penales que operan como refuerzo de aquéllas. En segundo lugar, a que puesto que cada vez es más evidente la aproximación de los nuevos tipos penales al modelo de intervención administrativa, mayor es el alejamiento de los principios clásicos del Derecho penal ${ }^{40}$. Así pues, con este nuevo modo de intervención penal aumentan las dificultades para establecer una distinción, no sólo cuantitativa sino también cualitativa, entre aquellas infracciones constitutivas de delito de aquellas que solamente representan un ilícito administrativo.

Tradicionalmente, se sostiene que la distinción entre ilícito penal e ilícito administrativo no sólo se fundamenta en el distinto contenido de injusto (dimensión cuantitativa), sino también en "los criterios de imputación de ese injusto y las garantías de diverso signo (formales y materiales) que rodean la imposición de sanciones al mismo" ${ }^{41}$. De este modo, se hace evidente la necesidad de prestar atención también a parámetros de diferenciación de naturaleza cualitativa. Precisamente, desde esta última perspectiva gana terreno la relevancia del criterio teleológico que inspira al Derecho penal y del correspondiente al Derecho administrativo sancionador. Como señala Silva Sánchez (2001), el Derecho penal "persigue proteger bienes concretos en casos concretos y sigue criterios de lesividad o peligrosidad concreta y de imputación individual de injusto propio", mientras que el Derecho administrativo sancionador "persigue ordenar, de modo general, sectores de actividad", siendo la afectación general y la peligrosidad estadística sus criterios inspiradores, sin necesidad de constatar la lesividad (incluyendo los supuestos de peligro concreto y de peligro abstracto u idóneo) para un bien jurídico en concreto ${ }^{42}$. Si bien esta es la diferenciación ideal, la realidad es que el Derecho penal actual cada vez se aproxima más a la lógica del Derecho administrativo sancionador, produciéndose, como señala la doctrina, "un proceso de difuminación de fronteras" ${ }^{43}$. Muestra de ello son tipos penales, como algu-

ese modo, la cualificación -como ilícito penal- de lo que hasta entonces se agotaba en un ilícito administrativo", p. 138.

39 Vid. Silva Sánchez, La expansión, $2^{\text {a }}$ ed., p. 123.

40 Vid. Baratta, en FS-Arthur Kaufmann, p. 401.

41 Vid. Silva Sánchez, La expansión, $2^{\text {a }}$ ed., p. 125.

42 Vid. Silva Sánchez, La expansión, $2^{\text {a }}$ ed., p. 125.

43 Vid. Feijóo Sánchez, en Derecho y justicia penal del s. XXI, p. 138. 
nos de los regulados entre los delitos contra la seguridad vial, en los que, más que basarse en criterios de lesividad e imputación individual, la atribución de responsabilidad penal se establece a partir de parámetros de lesividad o, mejor dicho, de peligrosidad global propios del Derecho administrativo o simplemente de desobediencia al orden administrativo. De este modo, la diferencia entre delito e ilícito administrativo se basa, en ocasiones, en un criterio puramente cuantitativo. El problema es que, con ello, el tipo penal se configura como un injusto formal carente de contenido material que lo diferencie del injusto administrativo correspondiente y, de ahí, en un tipo penal ilegítimo ${ }^{44}$.

\section{Aplicación al delito de conducción excesiva (art. 379.1) y al delito de conducción sin permiso o licencia (art. 384 CP)}

En el apartado anterior se ha hecho referencia, de forma general, al fenómeno de la administrativización del Derecho penal y a sus consecuencias principales. De lo que se trata ahora es de analizar si legislador, al tipificar las conductas actualmente previstas en el art. 379.1 y art. 384 CP ha procedido sobre la base de la lógica del Derecho penal o, más bien, siguiendo los parámetros del Derecho administrativo sancionador. En otras palabras, se trata de determinar si cabe o no continuar otorgando a estas figuras delictivas la calificación de delitos de peligro basados en criterios de lesividad material propios del Derecho penal.

Empecemos por el delito de conducción a una velocidad excesiva. Como ya se ha mencionado, en este caso el legislador parte de la tipificación de una conducta que considerada peligrosa en sí misma, sin necesidad de vincularla con la producción posterior de un resultado de peligro. Así, se escapa claramente de la figura de los delitos de peligro concreto, con lo que, entre otras cosas, facilita la tarea del juzgador que en su caso tenga que aplicar estos tipos ${ }^{45}$. El delito del art. 379.1 CP presupone, pues, una presunción iuris et de iure de la peligrosidad para la seguridad vial. ¿Es necesario que para aplicación de esta norma el juzgador constate que la conducta, en las condiciones en que se ejecuta, además de vulnerar las normas de tráfico, es idónea para originar un riesgo para el bien jurídico protegido? Conforme al tenor literal de este precepto, en el que se omite cualquier referencia a la ofensividad material de la conducta que fundamente el recurso a una interpretación teleológica restrictiva, el juez no tiene por qué plantearse la peligrosidad de la conducta en términos hipotéticos. El legislador le ha descargado de esa función ${ }^{46}$. El delito de conducción excesiva no es un

44 En este sentido, Feijóo Sánchez, en Derecho y justicia penal del s. XXI, pp. 155-157, señalando que "las normas penales que por su redacción impiden que materialmente se pueda encontrar la retribución de un injusto concreto merecedor de pena como organización defectuosa carecen de legitimidad”, p. 156.

45 Al respecto, García Albero, RECPC 09-11 (2007), pp. 11-13.

46 Prueba de ello es que las últimas sentencias dictadas a propósito del delito del art. 379.1 CP no se caracterizan, precisamente, por la compleja argumentación desarrollada por los tribunales para fundamentar la condena. Al contrario, estas resoluciones se limitan verificar la velocidad a la que conducía el sujeto, comparándola con la velocidad permitida en la vía concreta por la que se circulaba: vid., por ejem- 
delito de peligro para cuya afirmación sea necesario acreditar la idoneidad de la conducta en el caso concreto para afectar al bien jurídico protegido. Recordemos, la presunción que establece el legislador no es iuris tantum sino iuris et de iuret7. Por tanto, no estamos ni en presencia de un delito de peligro concreto ni tampoco ante un de peligro abstracto-concreto en el que se requiera que sea el juez quien constate la peligrosidad idónea de la conducta para afectar al bien jurídico. Con ello, se tendría que afirmar que estamos en presencia de un delito de peligro abstracto puro ${ }^{48}$, esto es, ante un delito que tipifica una conducta de peligrosidad formal o normativa. Ahora bien, a mi juicio, y a diferencia del tipo del art. $384 \mathrm{CP}$ al que seguidamente se presta atención, el delito previsto en el art. 379.1 CP es un tipo penal que se justifica sobre la base de la prevención de conductas que entrañan cierta peligrosidad, si bien es una peligrosidad vinculada a criterios de lesividad social o colectiva y no de lesividad concreta. El legislador le ahorra al juez la tarea de comprobar la idoneidad de la conducta para afectar al bien jurídico, siendo eso algo que aquél, sobre la base de datos empíricos, presupone como algo inherente a la conducción a una velocidad excesiva. Ahora bien, ni siquiera los que consideran que la función del Derecho penal es garantizar la vigencia de la norma convienen en la relevancia penal de esta clase de conductas sólo presunta o estadísticamente peligrosas ${ }^{49}$. Con todo, es cierto que se trata de un tipo penal más próximo al Derecho administrativo que no al Derecho penal.

En segundo lugar, con el delito de conducción sin permiso o licencia del art. 384 $\mathrm{CP}$ se pone de manifiesto que lo relevante para el castigo penal ya ni siquiera es el desvalor de la conducta o comportamiento desde la perspectiva de su capacidad de afectación al bien jurídico, sino solamente si de ese modo se consigue un mayor control de ciertas situaciones o ámbitos generales de peligro ${ }^{50}$. Mediante este tipo penal, el legislador permite imponer pena a supuestos que ni siquiera tienen por qué referirse a conductas que entrañan una peligrosidad real para la seguridad vial. En efecto, conducir a $200 \mathrm{Km}$./h o más por vía interurbana es una conducta siempre peligrosa, mientras que conducir sin haber obtenido nunca el permiso o licencia no siempre es una conducta peligrosa, ni siquiera desde la lógica del peligro a la colectividad. Consideradas individualmente, las infracciones penales que reclaman la aplicación del art. 384 resultan totalmente formales ${ }^{51}$. En efecto, según este precep-

plo, SAP-Lleida, Secc. $1^{\mathrm{a}}$, de 18 de septiembre de 2009 (ponente Chesa Celma); SAP-Alicante, Secc. $3^{\mathrm{a}}$, de 3 de julio de 2009 (ponente Ojeda Domínguez).

47 Vid. García Albero, RECPC 09-11 (2007), p. 16.

48 De la misma opinión, Gutiérrez Rodríguez (et. al.), Protección penal de la seguridad vial, p. 30.

49 Al respecto, Silva Sánchez, La expansión, 2. ${ }^{a}$ ed., pp. 140-141. Según Jakobs, precisamente uno de los autores que defienden la estabilización de las expectativas normativas como función del Derecho penal, tampoco cualquier "pequeña perturbación de la seguridad cognitiva” tiene que ser delito, vid. Jakobs, en El sistema funcionalista del Derecho penal, p. 54; también desde una perspectiva normativista de la función de la pena, señala Feijóo Sánchez, en Derecho y Justicia penal en el siglo XXI, que "la sanción de una conducta por realizar algo que, simplemente, es estadísticamente peligroso, pero que en el caso concreto no supone una organización defectuosa para otro ámbito de organización sólo se puede canalizar a través del Derecho administrativo", p. 155.

50 Así, Herzog, PJ 32 (1993), p. 86.

51 De la misma opinión, Gutiérrez Rodríguez (et. al.), Protección penal de la seguridad vial, p. 30. 
to deben castigarse con pena conductas que o bien suponen una actuación en contra del propio orden administrativo o bien en contra del orden judicial. Esta clase de comportamientos, sin más elementos añadidos, implican a lo sumo una vulneración del orden administrativo "de policía". De ahí que se entienda que esta clase de infracciones, para cuyo castigo también se prevé la pena de prisión, constituyen simplemente un ilícito de desobediencia. $Y$ es que, individualmente consideradas, no reúnen el desvalor material necesario que justifica la imposición de una pena y permite diferenciarlas de las infracciones administrativas. Es más, mediante el art. 384 CP el legislador prescinde de la peligrosidad, incluso de la de carácter colectivo o estadístico, como criterio inspirador de este tipo penal52. En definitiva, si bien la conducta tipificada en el art. 379.1 CP responde a la lógica de la peligrosidad, no sucede lo mismo con respecto al art. $384 \mathrm{CP}$, configurado como una simple desobediencia al orden administrativo ${ }^{53}$.

\section{CONSIDERACIONES FINALES}

La reforma en materia de delitos contra la seguridad vial que tiene lugar con la LO 15/2007, de 30 de noviembre ${ }^{54}$, pone de manifiesto la necesidad de que el Derecho penal se configure como una herramienta fundamental en el control del riesgo vial y, así, en la búsqueda de la tan demandada seguridad absoluta55. En una sociedad como la nuestra, imbuida en la "ideología de la seguridad" 56 , los ciudadanos no delincuentes ya no se muestran recelosos ante la intervención del poder punitivo. Al contrario, los derechos y libertades individuales ceden en favor de una mayor y más pronta intervención punitiva como medio para asegurar los espacios de riesgo ${ }^{57}$. En ámbitos como el aquí comentado, esta mayor intervención punitiva se materializa no solamente recurriendo a la técnica de los delitos de peligro concreto o idóneo, sino también a través de delitos de peligro abstracto puro o incluso de tipos formales. En efecto, puesto que se demanda y se tolera una mayor intervención punitiva de los poderes públicos, valorándose más la seguridad, se aceptan los delitos de peligro abstracto puros. Aunque éstos sean cuestionables desde la perspectiva de principios como el de lesividad, lo que realmente se valora es que "proporcionan una mayor seguridad jurídica en la definición y aplicación de los tipos penales" ${ }^{58}$.

Tanto el delito de conducción a una velocidad excesiva (art. 379.1 CP) como el delito de conducción sin permiso o licencia (art. 384 CP) son tipos penales que adoptan un contorno mucho más próximo a la lógica del Derecho administrativo sanciona-

52 En el mismo sentido, Sola Reche, $R G D P 10$ (2008), p. 31.

53 Vid. Montaner Fernández, en Lecciones de Derecho Penal. Parte especial, $2^{\text {a }}$ ed., p. 288.

54 Cuya orientación también se mantiene con la LO 5/2010, de 22 de junio.

55 Vid. Kuhlen, en Crítica y justificación del Derecho penal en el cambio de siglo, pp. 227-228.

56 Utilizando esta expresión, Pastor Muñoz, en Derecho penal del enemigo, pp. 525-526.

31857 Al respecto, Díez Ripollés, RECPC 06-03 (2004), p. 17. 
dor que al Derecho penal. Así pues, lo que se pretende evitar mediante la tipificación de estas conductas no es una concreta lesión o puesta en peligro para el bien jurídicopenal protegido que de ellas puedan derivarse, sino más bien impedir que la realización de tales conductas se repita, en tanto su acumulación sí supondría un riesgo global para la seguridad vial.

Por otro lado, estas nuevas figuras delictivas son reveladoras de la intención de nuestro legislador de tranquilizar a la sociedad frente a supuestos relacionados con el tráfico viario que causan cierta indignación o temor, aunque la intervención penal en estos supuestos suponga apartarse de los fundamentos que tradicionalmente la han inspirado. En efecto, a través de esta reforma en materia de delincuencia vial, el legislador penal antepone los efectos simbólicos o expresivos de la imposición de una pena a sus efectos instrumentales, pues más que una norma dirigida a la protección de un bien jurídico estamos ante un precepto con el que se pretende transmitir a la sociedad un mensaje de calma y de confianza en el ordenamiento jurídico-penal ${ }^{59}$. En esta medida, cobra protagonismo la función preventivo (general) del Derecho penal ${ }^{60}$. Es más, sin perjuicio de que la existencia de delitos como los aquí comentados pueda intimidar a potenciales delincuentes, la mayor eficacia de estas normas se tiene que valorar en relación con los ciudadanos fieles al Derecho. En efecto, recordemos que el motivo de la reforma del CP en materia de seguridad vial a través de la LO $15 / 2007$ es "incrementar el control sobre el riesgo tolerable" y además, con respecto al art. $384 \mathrm{CP}$, dar una respuesta jurídico-penal a "una criticada ausencia" como era "la conducción de vehículos por quienes hubieran sido privados, judicial o administrativamente" del permiso de conducir. Ahora bien, la cuestión es si la intervención del Derecho penal se legitima con algo más que un posible efecto tranquilizador para aquellos ciudadanos respetuosos con las normas.

En definitiva, lo que debemos preguntarnos es si estos nuevos tipos penales son una manifestación del denominado Derecho penal simbólico y, en concreto, de normas penales que carezcan de legitimidad no por la naturaleza de los efectos que provocan, sino porque éstos "no se acomodan a las decisiones políticocriminales que fundamentan la pena" ${ }^{61}$. Uno de los supuestos en los que se señala dicha ilegitimidad es precisamente cuando no se respetan las exigencias del principio de subsidiariedad de la intervención penal, como sucede con las denominadas "leyes apaciguadoras", cuya función es fundamentalmente la de "calmar las reacciones emocionales que ciertos sucesos han producido entre la ciudadanía"62. Precisamente, tipos penales

59 Respecto a esta distinción entre efectos instrumentales y simbólicos de la pena, vid. Díez Ripollés, en Crítica y justificación del Derecho penal en el cambio de siglo, pp. 150-152; en la misma línea, Kindhäuser, InDret 1/2009, señalando que "los temores se apaciguan mediante la prevención y la necesidad de prevención se sacia mediante el recurso a las sanciones del Derecho penal. De esta manera, el Derecho penal se convierte, expresado en términos informales, en "arma multiusos" del aseguramiento social", p. 4 .

60 Vid. Baratta, en FS-Arthur Kaufmann, p. 412.

61 Vid. Díez Ripollés, en Crítica y justificación del Derecho penal en el cambio de siglo, p. 164.

62 Vid. Díez Ripollés, en Crítica y justificación del Derecho penal en el cambio de siglo, p. 168. 
como el art. 379.1 y el art. 384 CP planean sobre este terreno. Aunque su existencia conlleve efectos intimidatorios, no puede decirse que la reacción penal se fundamente en la capacidad lesiva de las conductas en él reguladas. De este modo, parece que la única vía para salvar esta carencia de lesividad y poder así legitimar su aplicación sería proceder a una interpretación teleológica y restrictiva de los mismos. Sin embargo, esto es algo que excluye el propio tenor literal de ambos tipos penales.

\section{BIBLIOGRAFÍA}

Alcácer Guirao, R. (2002), “La protección del futuro y los daños cumulativos”, RECPC 04-08: 1-30.

Baratta, A. (1993), “Jenseits der Strafe -Rechtsgüterschutz in der Risikogesellschaft”, en Festschrift für Arthur Kaufmann zum 70. Geburtstag, Heidelberg: C.F. Müller: 393-416.

Cerezo Mir, J. (2002), “Los delitos de peligro abstracto en el ámbito del Derecho penal del riesgo", $R D P C$ 10: 47-72.

Corcoy Bidasolo, M. (1999), Delitos de peligro y protección de bienes jurídico-penales supraindividuales, Valencia: Tirant lo Blanch.

Corcoy Bidasolo, M. (2008), "Protección de bienes jurídico-penales supraindividuales y Derecho penal mínimo”, en Mir Puig, S. (Dir.), CGPJ: Derecho penal del s. XXI, Madrid: 363-402.

De Vicente Martínez, R. (2008), Derecho penal de la circulación, $2^{\mathrm{a}}$ ed., Barcelona: Bosch.

Díez Ripollés, J. L. (2003), “El Derecho penal simbólico y los efectos de la pena”, en Arroyo Zapatero, L./Neumann, U./Nieto Martín, A. (coords.), Crítica y justificación del Derecho penal en el cambio de siglo, Cuenca: Universidad de Castilla-La Mancha: 147-172.

Díez Ripollés, J. L. (2004), “El nuevo modelo penal de la seguridad ciudadana”, en RECPC 06-03: 1-34.

Feijóo Sánchez, B. (2005), "Seguridad colectiva y peligro abstracto. Sobre la normativización del peligro”, en Homenaje al Profesor Dr. Gonzalo Rodríguez Mourullo, Cizur Menor: Civitas: 307-342.

Feijóo Sánchez, B. (2006), "Sobre la "administrativización” del Derecho penal en la "sociedad del riesgo", en Derecho y justicia penal en el s. XXI: liber amicorum en homenaje al profesor Antonio González-Cuéllar García, Madrid: Colex: 136-176.

García Albero, R. (2007), “La nueva política criminal de la seguridad vial”, RECPC 09-11: 1-28.

Gutiérrez Rodríguez, M./ García del Blanco, V./ Martín Lorenzo, M./ Sanz-Díez de Ulzurrun Lluch, M. (2009), Protección penal de la seguridad vial, Valencia.

Hefendehl, R. (2002), “¿Debe ocuparse el Derecho penal de riesgos futuros? Bienes jurídicos colectivos y delitos de peligro abstracto” (trad. Salazar Ortuño, E.), RECPC 04-14: 1-13.

Hefendehl, R. (2007), “El bien jurídico como eje material de la norma penal” (trad. Martín Lorenzo, M.), en Hefendehl, R. (Ed.), Alcácer, R./ Martín, M./ Ortiz de Ur- 
bina, I. (Ed. Española), La teoría del bien jurídico. ¿Fundamento de legitimación del Derecho penal o juego de abalorios dogmáticos?, Madrid-Barcelona: Marcial Pons: 179-196.

Hefendehl, R. (2008), “El bien jurídico: imperfecto pero sin alternativa” (trad. Martín Lorenzo, M.), en García Valdés, C./ et. Al. (coords.), Estudios penales en homenaje a Enrique Gimbernat, tomo I, Madrid: Edisofer: 389-404.

Herzog, F. (1993), "Límites del Derecho penal para controlar los riesgos sociales", en PJ 32: 79-88.

Jakobs, G., (2000), “¿Qué protege el Derecho penal: bienes jurídicos o la vigencia de la norma?" (trad. Cancio Meliá, M.), en El sistema funcionalista del Derecho penal: ponencias presentadas en el II Curso Internacional de Derecho Penal. (Lima, 29-31 de agosto y 1 de septiembre de 2000), Lima: Grijley: 43-60.

Kindhüaser, U. (2009), “Estructura y legitimación de los delitos de peligro del Derecho penal" (trad. Pastor Muñoz, N.), InDret 1/2009: 1-19.

Kuhlen, L. (2003), "El Derecho penal del futuro" (trad. Nieto Martín, A.), en Arroyo Zapatero, L./Neumann, U./Nieto Martín, A. (coords.), Crítica y justificación del Derecho penal en el cambio de siglo, Cuenca: Universidad Castilla-La Mancha: 225-229.

Mata Martín, R. (1997), Bienes jurídicos intermedios y delitos de peligro, Granada: Comares.

Montaner Fernández, R. (2009), "Delitos contra la seguridad vial”, en Silva Sánchez (Dir.)/Ragués i Vallès (coord.), Lecciones de Derecho Penal. Parte especial, $2^{\mathrm{a}}$ ed., Barcelona: Atelier: 271-291.

Montaner Fernández, R. (2009), “El nuevo delito de conducción sin permiso: ¿delito de peligro o mera desobediencia?”, Diario La Ley (7170).

Moreno Alcázar, M. A. (2003), Los Delitos de conducción temeraria: criterios para la coordinación de los artículos 381 y 384 del Código penal, Valencia: Tirant lo Blanch.

Orts Berenguer, E. (2008), "Delitos contra la seguridad colectiva (y III): Delitos contra la seguridad vial”, en Vives Antón, T. S. (et. Al.), Derecho Penal. Parte Especial, 2. ed., Valencia: Tirant lo Blanch: 589 y ss.

Pastor Muñoz, N. (2006), "El hecho: ¿ocasión o fundamento de la intervención penal? Reflexiones sobre el fenómeno de la criminalización del "peligro de peligro", en Cancio Meliá, M. / Gómez-Jara Díez, C. (coords.), Derecho penal del enemigo. El discurso penal de la exclusión, Vol. II, Montevideo-Buenos Aires: B. de F.: 523-548.

Prieto González, H. M. (2008), "El delito de conducción sin permiso en la reforma de los delitos contra 'la seguridad vial”', en Mir Puig, S./Corcoy Bidasolo, M. (Dirs.), Cardenal Montraveta, S. (Coord.), Seguridad Vial y Derecho penal, Valencia: Tirant lo Blanch: 250-281.

Queralt i Jiménez, J., (2008), “El nuevo Derecho penal vial: generalidades críticas”, en Mir Puig, S./Corcoy Bidasolo, M. (Dirs.), Cardenal Montraveta, S. (Coord.), Seguridad Vial y Derecho penal, Valencia: Tirant lo Blanch: 63-71.

Requejo Conde, C. (2009), "Las nuevas modalidades de delitos contra la seguridad vial en el Código Penal”, Tráfico y Seguridad Vial. La Ley (132).

Rodríguez Montañés, T. (1994), Delitos de peligro, dolo e imprudencia, Madrid: Universidad Complutense de Madrid.

Schröder, H. (1969), “Die Gefährdungsdelikte im Strafrecht”, ZStW 81: 7-28. 
Silva Sánchez, J. M. (2001), La Expansión del Derecho penal, $2^{a}$ ed., Madrid: Civitas.

Sánchez Lázaro, F. G. (2010), "Deconstruyendo el riesgo permitido. Delitos contra la salud pública, principio de precaución, delitos contra la seguridad vial”, Revista penal (25): 136-150.

Sola Reche, E. (2008), "Los viejos problemas de los nuevos delitos contra la seguridad vial", RGDP 10: 1-35.

Recibido: 19 de abril de 2010

Aceptado: 8 de junio de 2010 